\title{
A Study on Features of Zhu Ziqing's Prose and Its Translation-With Special Reference to His Hetang Yuese
}

\author{
Ying Yang \\ School of International Education, Shandong Economic University, Jinan, Shandong, China \\ Email: ccyangying@126.com
}

\begin{abstract}
As a prominent prose writer in modern Chinese literature, Zhu Ziqing is known for his touching and thought-provoking language. The words and expressions he chooses are both vivid and succinct, bringing readers aesthetic feelings. In order to successfully represent the aesthetic values in the English version, a translator needs to do a deep-going research into the artistic features in his prose works and tries to reproduce them in the version so as to realize the ultimate goal of prose translation-similarity in spirit.
\end{abstract}

Index Terms - Zhu Ziqing, prose translation, artistic features, similarity in spirit

\section{INTRODUCTION}

Zhu Ziqing (1898-1948) is an outstanding Chinese prose writer as well as a famous poet, whose style of writing is characterized by a kind of simple and profound beauty. He succeeds in achieving a fusion of the conveyance of feelings with the description of scenery, producing artistic conceptions full of poetic charm and leading the reader into an artistic realm. Rich in vivid images, his lyric prose can inspire the reader with fertile association and imagination. When it comes to translating his prose works into English, a translator should bear it in mind that the original aesthetic values need to be represented in the English version. Prose translation, as one kind of translation, also aims at making sure "the readers of a translated text should be able to comprehend it to the point that they can conceive of how the original readers of the text must have understood and appreciated it" or "the readers of a translated text should be able to understand and appreciate it in essentially the same manner as the original readers did" (Nida, 1993, p.118). To realize this goal, the first step taken by a translator is to fully appreciate the beauty and analyze the features of Zhu's prose works.

\section{ZHU'S LYRIC PROSE LANGUAGE}

Zhu Ziqing's lyric prose successfully fulfils the function of conveying the meaning and expressing the feeling, which is the soul of the aesthetic features in his prose. The reason why his prose can bring readers such aesthetic feelings is none other than his fresh and natural language that is novel, poetic and musical.

\section{A. Novel}

The vividness of language should take novelty as the premise. Every new object needs to be expressed in a new language form. It is impossible to vividly show the ever-changing characters of objects if one always follows what other people say. Zhu Ziqing is apt at tapping the treasure of language and bold to innovate in prose language. He prefers non-westernized spoken language, however, he does not absolutely reject westernization. Actually, he selectively introduces some westernized elements into his prose language so as to increase a sense of freshness.

\section{A Suffix “着”}

In imitation of the English suffix, he makes use of the verbal suffix “着” in Chinese to achieve two goals: one is to change the part of speech; the other is to show the continuous movement of the object described. In this way, he not only increases the novelty of language but also adds poetic flavor to his lyric prose. For Example:

但是河中眩晕着的灯光, 纵横着的画舫, 悠扬着的笛韵, 夹着那吱吱的胡琴声, 终于使我们认识绿如茵陈酒 的秦淮水了。

But the glimmering lantern lights, the pleasure-boats floating here and there and the melodies played on flutes and fiddles gradually showed us that the water of the Qinhuai was as green as artemisia wine.

Here, the Chinese words “眩晕”, “纵横” and “悠扬” are adjectives. The writer changes them into verbs by adding the verbal suffix “着” behind them to show the continuous action. While in the English versions, the translator adopts different ways of expression to represent this feature. Both the adverb "always" and the present participles like "glimmering" and "floating" indicate the continuous state of the things described. If “悠扬着的笛韵” is translated into "....and the mellifluous notes flowing from flutes and fiddles", the effect would be much better. 


\section{Syntactical Inversion}

Unusual sentence patterns can sometimes be especially forceful and elegant. Normally a sentence moves from subject to verb to complement, but inversion is a departure from the customary arrangement of words. To enliven and vary the writing style, Zhu Ziqing sometimes applies the English inversion to his prose writings. On the one hand, the inverted word or phrase gets greater emphasis than it did when buried in the normal position of the sentence. On the other hand, the inversion can contribute to a pleasing variety in sentence structure. For example:

山上不但可以看山, 还可以看谷, 稀稀疏疏错错落落的房舍, 仿佛有鸡鸣犬吠的声音, 在山肚里, 在山脚下。 The author's version:

You can catch sight of mountain range as well as mountain valley. There seems to be the crowing of cocks and the barking of dogs coming out from the sparsely scattered houses, on the hillside or at the foot of the hill.

According to the usual practice of modern Chinese, the adverbial is often placed before the predicate. But Zhu Ziqing purposefully inverts it after the predicate. As the adverbial, the prepositional structure “在山肚里, 在山脚下” is found after the predicate. The inverted sentences sound quite natural and graceful, free from any kind of affectation. The versions just follow the English way of expression with few alterations.

\section{B. Poetic}

Yu Dafu, a modern Chinese short story writer and poet, praised Zhu's prose for a kind of poetic charm permeating through it. This is really true. The beauty of his lyric prose lies in its poetic flavor as well as the vivid description of scenery. Language should be appropriately embellished, but this does not contradict with the simplicity of style. One couplet frequently quoted reads like this: (“欲把西湖比西子, 淡妆浓抹总相宜。”)

The West Lake looks like the fair lady at her best,

Whether she is richly adorned or plainly dressed.

Either "richly adorned" or "plainly dressed" language will increase the vividness of prose, as long as it is properly handled. Zhu Ziqing attaches much importance to the artistic expressiveness of language. The following aspects may contribute to a better appreciation of his poetic language.

\section{Active Verbs}

In the preface to his anthology called Miscellany of Europe, he says the following words: "It is the most difficult to arrange the Chinese sentence patterns with the characters '是' (be), ‘有' (have or has), and '在' (in, at...). To show the positional relations among the objects, it is hard to avoid using these three patterns. But who would be patient with the stereotyped all the time? It would be unbearably oppressive since all these patterns show a static state. So I try every means to omit these three disgusting characters. Of course I would be happier to turn something static into dynamic, e.g. 'A child appeared from under his left arm.' "' He earnestly practices what he himself advocates.

In his lyric prose, one has no difficulty finding many elaborately chosen verbs. Verbs are the liveliest and the most active factor in language, which can immediately enliven the things described and add vividness to them. If verbs are properly selected to depict the static scenery, the original static things will be animated with action and will look more lifelike so as to inspire the reader's association and increase his interest.

天黑时, 我躺在床上, 他便伶伶俐俐地从我身上跨过, 从我脚边飞去了。等我睁开眼和太阳再见, 这又算溜 走了一日。但是新来的日子的影儿又开始在叹息里闪过了。(《勿匀》)

In the evening, as I lie in bed, he strides over my body, glides past my feet, in his agile way. The moment I open my eyes and meet the sun again, one whole day has gone. But the new day begins to flash past in the sigh. (Tr. Zhu Chunshen)

The image of time, described by the writer, is continuously moving: it nimbly “跨过”, briskly “飞去”, quietly “溜走”, and rapidly "闪过". Similarly, the four active verbs "stride over", "glide past", "go" and "flash past" in the English version vividly show the fleeting feature of time, impressing the lively portrayal of time upon the reader. It seems that he can hear the light footsteps of time.

\section{Metaphorical Expressions}

Newmark (2001) argues that good writers use metaphors to help the reader to gain a more accurate insight, both physical and emotional, into a character or a situation. Zhu Ziqing is quite adept at handling various rhetorical devices to present the objects vividly before the reader and evoke his rich imagination. Among them, metaphor in his lyric prose helps to create the vivid images and increase the poetic flavor of his language. For example:

春天象刚落地的娃娃, 从头到脚都是新的, 它生长着。

春天象小姑娘, 花枝招展的, 笑着, 走着。

春天象健壮的青年, 有铁一般的胳膊和腰脚, 他领着我们上前去。(《春》)

The author's version is as follows:

Spring is like a newly born baby, gradually developing itself.

Spring is like $\boldsymbol{a}$ girl gorgeously dressed, smiling and walking.

Spring is like a robust young man with muscles of iron, leading us forward.

His work entitled Spring is praised to be a prose poem. Zhu Ziqing uses metaphor throughout this famous writing. Zheng (2002) believes that while dealing with rhetorics like metaphors, translators are expected to retain the original 
metaphors in the version as long as the target readers can understand them, although there are no such metaphors in the receptor language. In these three parallel sentences, spring is first compared to "a newly born baby" to show its exuberant vitality, then it is likened to "a girl", showing its beauty and liveliness and finally it is compared to "a robust young man" implying its youthful spirit. All these three metaphors are very appropriate because they leave readers vivid and concrete images and help them to feel spring in a progressive way.

In short, the proper use of both active verbs and metaphorical expressions can add vividness and vitality to the objects described, formulate a concentrated imaginative awareness of experience, and provoke a specific emotional response on the part of the reader, thus helping to create poetic flavor or charm in Zhu's lyric prose writings.

\section{Musical}

Literary language is featured by the beauty of sound or musicality, for example, there are quite a lot of words containing two syllables in modern Chinese, among which reduplicated words accounts for a large proportion (Lin, 2002). These words have strong rhythm producing harmonious sounds. Therefore, when doing Chinese-English translation, a translator should spare no efforts to represent the original beauty in sound in the English version. Musicality is another striking artistic feature of Zhu Ziqing's lyric prose. He strives for the beauty of harmonious sounds, and this can be seen from his frequent exercise of reduplicated words in most of his lyric prose. Besides, one can easily find many parallel structures in Zhu's lyric prose. They help to create the relatively balanced intonation and hence produce a kind of symmetrical beauty in sound. The following part will focus on the discussion of the two aspects.

\section{Reduplication}

One of the most remarkable stylistic features of Zhu's lyric prose lies in the frequent use of reduplication or reduplicated words. Such words greatly enhance the musicality of his prose language. Reduplication is peculiar to the Chinese spoken language. Zhu brings this trait into full play in his prose works.

早上我起来的时候, 小屋里射进两三方斜斜的太阳。太阳他有脚啊, 轻轻悄悄地挪移了; 我也茫茫然跟着旋 转。(《勿勿》)

Version I:

When I get up in the morning, the slanting sun casts two or three squarish patches of light into my small room. The sun has feet too, edging away softly and stealthily. And without knowing it, I am already caught in its revolution. (Tr. Zhang Peiji)

Version II:

When I get up in the morning, the slanting sun marks its presence in my small room in two or three oblongs. The sun has feet, look, he is treading on, lightly and furtively; and I am caught, blankly, in his revolution. (Tr. Zhu Chunshen)

In this example Zhu Ziqing uses three reduplicated words like “斜斜”, “轻轻悄悄”and “茫茫然”. The use of these words helps the reader see and hear the elapse of time. Obviously, both the translators pay attention to this feature. "轻 轻悄悄" is respectively rendered into adverbs "softly and stealthily" in Version I and "lightly and furtively" in Version II. By comparison, the alliteration in the former is much better than the two adverbs combined together in the latter as it reproduces the original musicality in a way conforming to the English expression. Both the two translators adopt free translation to deal with “茫茫然”, for it is rendered into a prepositional phrase “without knowing it” in Version I and an adverb "blankly" in Version II.

\section{Parallel Structure}

Strictly speaking, parallel structure can first give the reader visual enjoyment because of its regular form. But it can bring forth audio pleasure because of the inherent rhythm as well. Let us look at some examples:

(1) 燕子去了, 有再来的时候; 杨柳枯了, 有再青的时候; 桃花谢了, 有再开的时候。(《匀匀》)

Swallows may have gone, but there is a time of return; willow trees may have died back, but there is a time of regreening; peach blossoms may have fallen, but they will bloom again. (Tr. Zhu Chunshen)

The original triple parallelism is full of strong vigor with regular rhythms. The English version employs the corresponding sentence patterns to retain this feature. But to avoid monotony caused by undue repetition, the translator makes a little change in the final sentence instead of saying "but there is a time of reblooming."

(2) 于是一一洗手的时候，日子从水盆里过去; 吃饭的时候，日子从饭碗里过去; 默默时，便从凝然的双眼 前过去。（Ibid）

Thus the day flows away through the sink when I wash my hands; vanishes in the rice bowl when I have my meal; passes away quietly before the fixed gaze of my eyes when I am lost in reverie. (Tr. Zhang Peiji)

The same sentence patterns are arranged in a streamline, so it seems as if the reader could see the flow of time. Most of the clauses are short, giving him a feeling of liveliness. The syntactical structure is quite simple with few changes, just like a continuously flowing river. The musicality lies in the smoothness of sentence rather than the cadence of syllables. The writer uses the distinct colloquial expressions to reveal the poetic charm freely. The rhythm of language coincides with the anxious state of mind in a natural way. In the version, the repetitive word “过去” of the original is respectively rendered into "flow away", "vanish" and "pass away" according to different contexts.

The above-mentioned aspects are general features of Zhu's lyric prose. As for one specific essay, some other characters will appear. In the following part, the author will further study the translation of his lyric prose by comparing 
two versions of his famous work.

\section{ANALYSIS AND COMPARISON OF TwO ENGLISH VERSIONS OF ZHU'S HETANG YUESE}

Hetang Yuese (Moonlight over the Lotus Pond), as one of Zhu's representative prose writings, enjoys a high reputation in modern Chinese prose. What this lyric prose expresses is the writer's subtle feelings through the minute description of the lotus pond in the moonlight. This prose writing is composed in a graceful way like a slim girl with elegant bearing, or a whiff of cool breeze pleasing to our heart. Zhu Ziqing successfully blends his inner feeling with the natural setting. At the same time, his artistic techniques also contribute to adding poetic flavor. He gives full play to his fantastic imagination to create vivid and lively images by choosing appropriate verbs and adjectives, applying original rhetorical devices and so on. Both the artistic appeal contained and the images described in this essay are represented through its language. It is the poetic language that gives the reader aesthetic feelings.

To translate such elegant writing into idiomatic English, it is impossible for a translator to do without being artistically accomplished and capable of handling the target language. Besides, as Zhang (1987) says, it is possible for a translator to represent the original artistic features. However, because there are big differences between the two languages, the words, sentence patterns and rhetorics may not be fully transplanted into the version, but at least part of them can be done. In this part, the author intends to discuss how to convey the original aesthetic properties from different aspects by comparing Version I by Zhu Chunshen with Version II by Wang Jiaosheng. The two translators enjoy high reputation in literary translation. Either version has its strong points in conveying meaning and expressing feeling.

\section{A. Choice of Words}

Hetang Yuese is usually seen as a wash painting full of freshness and elegance. We must admit that some nouns, verbs and adjectives in this prose play a decisive role in creating vivid images. Therefore, "figurative meaning is a frequent technique to attract attention" (Nida, 2001, p. 167). In translation, the words chosen should not only be equivalent to those in the source text in semantic meaning but also reflect the original style.

（1）沿着荷塘，是一条曲折的小煤屑路。这是一条幽僻的路; 白天也少人走，夜晚更加寂寞。荷塘四面，长 着许多树, 萮薪郁郁的。没有月光的晚上, 这路上阴森森的, 有些怕人。今晚却很好, 虽然月光也还是淡淡的。

Version I:

Alongside the Lotus Pond runs a small cinder footpath. It is peaceful and secluded here, a place not frequented by pedestrians even in the daytime; now at night, it looks more solitary, in a lush, shady ambience of trees all round the pond. The foliage, which, in a moonless night, would loom somewhat frighteningly dark, looks very nice tonight, although the moonlight is not more than a thin, grayish veil.

Version II:

A path paved with coal-dust zigzags along the lotus pond, so secluded as to be little frequented in the daytime, to say nothing of its loneliness at night. Around the pond grows a profusion of luxuriant trees. On moonless nights, the place has a gloomy, somewhat forbidding appearance. But on this peculiar evening, it had a cheerful outlook, though the moon was pale.

The original adjective “曲折的” is rendered into verbs "run" and "zigzag" respectively. The latter is better, for it vividly describes the appearance of the path. The reduplicated word “落荨郁郁” is rendered into “a lush, shady ambience" in Version I. On the one hand, the translator adopts liberal translation to reproduce the original meaning; on the other hand, the repeated sound /sh/ implies that there are many trees, and the writer's melancholy mood is exposed as well. In Wang's version, the phrase "a profusion of luxuriant trees" only reproduces the original meaning accurately, but its aesthetic effect is not as strong as that of Zhu's version. Finally, “淡淡的” is translated into "a thin, grayish veil" in Version I, which is actually a wonderful metaphor. The adjectives "thin, grayish" together with the noun "veil" bring the readers visual enjoyment as if they could view the pale moon through a thin veil. While in Version II, "the moon was pale" is no more than a narrative statement, lacking poetic flavor.

(2) 月光如流水一般, 静静地泻在这一片叶子和花上。薄薄的青雾浮起在荷塘里。叶子和花仿佛在牛乳中洗 过一样, 又象笼着轻纱的梦。

Version I:

The moon sheds her liquid light silently over the leaves and flowers, which, in the floating transparency of a bluish haze from the pond, look as if they had just been bathed in milk, or like a dream wrapped in a gauzy hood.

Version II:

Moonlight was flowing quietly like a stream down to the leaves and flowers. A light mist overspread the lotus pond. Leaf and flower seemed washed in milk.

In this example, the original four verbs are properly used to effectively express the writer's slight joy. In Version I the word "shed" has to do with both light and water, and the connotation of it is richer than that of "flow" in Version II. "浮 起" is rendered into the present participle "floating", which shows the continuous action while the word "overspread" fails to reveal the dynamic state of mist. If something is described as bathed in light or moonlight, this really means that light makes it look pleasant or attractive. "Bathe" used together with "milk" gives more prominence to the cleanness of 
lotus flowers than the word "wash". Finally, the verb "wrap" points out the misty and obscure state of this specific scene. What is more, “流水”, “青雾”, “轻纱” are respectively translated into "liquid light”, "bluish haze” and "gauzy hood" in Version I so that the original beauty of haziness can be further perceived by the TL readers. Therefore, Version I better transfers the original beauty in sense by seeking the most suitable words.

Among the adjectives, reduplicated words occupy a large proportion. The frequent use of reduplicated words is one of the striking stylistic features in Hetang Yuese, which shows Zhu's pursuit of musicality in his works. There are altogether 26 reduplicated words appearing in this essay, among which some like “田田” and “亭亭” are even borrowed from the Chinese classic poetry. These words are conductive to producing cadenced rhythm.

(3) 曲曲折折的荷塘上面, 弥望的是田田的叶子, 叶子出水很高, 像亭亭的舞女的裙。

Version I:

All over this winding stretch of water, what meets the eye is a silken field of leaves, reaching rather high above the surface, like the skirts of dancing girls in all their grace.

Version II:

On the uneven surface of the pond, all one could see was a mass of leaves, all interlaced and shooting high above the water like the skirts of slim dancing girls.

In the original sentence appear three reduplicated words. Whether they are successfully translated is the key to the translation of the whole sentence. In Version I, the translator resorts to the English alliteration "winding...water, what..." to obtain the similar effect; “田田” is translated into “a silken field" with a view to catching tactile sensation; “亭亭” into a prepositional phrase “in all their grace” from the perspective of semantic meaning. Besides, there also exists another group of alliteration sounds formed by the words "stretch", "silken", "surface" and "skirts". In Version II, the three reduplicated words in the original are replaced by "uneven, mass, slim", which the author thinks fail to reproduce the original beauty in sound. There is no denying that it is challenging for a translator to make "the choice of a suitable equivalent" (Baker, 2000, p. 18) in the version.

\section{B. Rhetorical Devices}

Almost all the images created in this prose writing embody the writer's rich imagination. The novel rhetorical devices like metaphor and personification play a positive role in giving a quiet and beautiful view of the lotus pond at night. At the same time, rhetorical devices contribute to increasing poetic charm of the whole work by highlighting the images of what the writer describes. For example:

(1) 层层的叶子中间, 零星地点缀着些白花, 有哀娜地开着的; 有差涩地打着朵的; 正如一粒粒的明珠, 又 如碧天里的星星, 又如刚出浴的美人。

Version I:

Here and there, layers of leaves are dotted with white lotus blossoms, some in demure bloom, others in shy bud, like scattering pearls, or twinkling stars, or beauties just out of the bath.

Version II:

The leaves were dotted in between the layers with white flowers, some blooming gracefully; others, as if bashfully, still in bud. They were like bright pearls and stars in an azure sky.

In this example, Zhu Ziqing uses both simile and personification to depict lotus flowers in great detail, as they are the most indispensable part of the pond. The flowers, as described by him, are endowed with human qualities. White flowers symbolize purity and reflect the writer's inner world. In Version I, the translator first uses a parallel structure "some in demure bloom, others in shy bud", in which the adjectives "demure" and "shy" are effective in likening flowers to charming young ladies; what is more, the similes "like scattering pearls, or twinkling stars, or beauties just out of the bath" faithfully reproduce the postures of lotus flowers, bringing aesthetic feelings to the readers and arousing their association and imagination. The merit in Version II lies in the use of the verb "bloom" together with two adverbs "gracefully" and "bashfully" so that the flowers are full of dynamic beauty. However, as the original similes are simply rendered into "like bright pearls and stars in an azure sky", the original appeal gets weakened to some degree.

When using metaphor to describe scenery, Zhu Ziqing does not content himself with the display of visual image. In this essay, he uses another important rhetorical device-synaesthesia (different sensations mutually linked up by the writer when he describes scenery, with one sensation compared to another). Actually, this is an odd metaphor provoked by artistic association. He tends to endow the silent scene with sounds, so the reader may get a strange experience of what he depicts.

(2)微风过处, 送来缕缕清香, 仿佛远处高楼上泪茫的歌声似的。

Version I: A breeze stirs, sending over breaths of fragrance, like faint singing drifting from a distant building.

Version II: Their subtle fragrance was wafted by the passing breeze, in whiffs airy as the notes of a song coming faintly from some distant tower.

(3) 塘中的月色并不均匀, 但光与影有着和谐的旋律, 如梵邚玲上奏着的名曲。

Version I: The moonlight is not spread evenly over the pond, but rather in a harmonious rhythm of light and shade, like a famous melody played on a violin.

Version II: Uneven as was the moonlight over the pond, there was a harmony between light and shade, rhythmic as a 
well-known melody played on the violin.

In example (2), the sense of smell is compared to the sense of hearing because breaths of fragrance and indistinct singing have faintness in common; in example (3), the visual sense is also compared to the sense of hearing because harmony is seen as the resemblance between "light" mingled with "shade" and "a famous melody played on the violin." Therefore, when the reader appreciates the beautiful scene of lotus pond, it seems as if he could hear the faint singing or the melodious notes from the violin. Now let us see how the two translators deal with this metaphor respectively.

Both the translators use simile with "as..." or "like..." to show the similarity between the tenor and the vehicle. The author prefers Version II because the two tenors "fragrance" and "harmony" are highlighted while the first version seems to center on other things like "breeze" or "moonlight". In addition, the adjective phrases "airy as..." and "rhythmic as ..." function as the complements, which clearly point out the similarities between different sensations. Therefore, the TL readership can be led into a more secluded realm, so it is easy for them to realize the implication the writer intends to transmit. In Version I, the clauses are loosely organized and vague in meaning. One might as well change "played" into "being played". It can be regarded as the continuous tense of passive voice "be played" or the passive voice of the gerund "playing". In this way, Version II will better fit in with the context and provide audio enjoyment to TL readership.

\section{Structural Characters}

The structural characters in this essay are reflected in syntactical parallelism and "repetition of words or phrases for emphasis (Nida, 2001, p. 211). Chinese and English have much in common in this aspect, that is, the aesthetic features can be achieved through the combination of sound, form and sense. The repetitive structures containing the variable components can give emphasis to the relationship between parallel words. This relationship can be equilibrium or contrast. The syntactical parallelism effectively enhances a sense of rhythm, which is the essence of musicality. Almost all the parallel sentences in this essay are either the writer's direct comment on something or his inner soliloquy. For example:

（1）我爱热闹，也爱冷静；爱群居，也爱独处。像今晚上，一个人在这苍茫的月下，什么都可以想，什么都 可以不想, 便觉是个自由的人。白天里二定要做的事, 一定要说的话, 现在都可不理。(《荷塘月色》)

I like a serene and peaceful life, as much as a busy and active one; I like being in solitude, as much as in company. As it is tonight, basking in a misty moonshine all by myself, I feel I am a free man, free to think of anything, or of nothing. All that one is obliged to do, or to say, in the daytime, can be very well cast aside now. (Tr. Zhu Chunshen)

This paragraph is strikingly featured by the frequent use of parallel structure, by which the writer can easily express his contradictory psychology and then give prominence to his strong desire for a free, serene and happy life. What impresses the reader most is the symmetrical form of parallel structures together with the accompanying accented rhythms. The translator takes this characteristic into full consideration by adopting several well-balanced structures like "a serene and peaceful life" and "a busy and active one", "in solitude" and "in company", "think of anything" and "or (think) of nothing", etc., with a view to preserving the beauty of coherence and equilibrium as well as the original musicality.

(2) 这时候最热闹的，要数树上的蝉声和水里的蛙声；但热闹是它们的，我什么也没有。

Version I:

The most lively creatures here, for the moment, must be the cicadas in the trees and the frogs in the pond. But the liveliness is theirs, I have nothing.

Version II:

At this moment, most lively were the cicadas chirping in the trees and the frogs croaking under the water. But theirs was all the merry-making, in which I did not have the least share.

In the original text, the noise from cicadas and frogs set off the serenity of the surroundings and with the background noise, the writer's depressed mood is conspicuous to be perceived by the reader. As to this partial parallel structure, both translators copy the form but the effects are quite different. In Version II, the two onomatopoeias "chirp" and "croak" in the parallel structures vividly reproduce the noise made by cicadas and frogs. Besides, the participial form of the two words suggests the continuity of noise. Compared with Version II, the first version fails to transmit the original meaning though it retains the form of the source text.

Besides parallel structure, inversion can be viewed as another structural character though it is not as remarkable as the former in this prose writing. It can bring the reader some freshness after he reads many a normal sentences. A pleasing variety in sentence structure can be achieved by means of inversion. What is more, the inversion may promote greater continuity between sentences. For example:

（3）树梢上隐隐约约的是一带远山，只有些大意罢了。树缝里也漏着一两点路灯光，没精打采的，是渴睡人 的眼。

Version I:

Over the trees appear some distant mountains, but merely in sketchy silhouette. Through the branches are also a couple of lamps, as listless as sleepy eyes.

Version II:

Distant hills loomed above the treetops in dim outline. Here and there, a few rays from street-lamps filtered through 
the trees, listless as the eyes of one who is dozing.

The reason why the writer chooses inversion lies in that both subjects in the two sentences “远山” and “路灯光” have their respective post modifiers. In this way, the sentence will look more compact. The author prefers Version I because it preserves the original sentence pattern. And the inverted sentence indeed enables the semantic coherence between the clauses. Seen from the perspective of coherence and continuity, Version II is inferior to Version I.

It is clear that each version has its own merits and demerits in different aspects. But on the whole, the author believes Zhu's version is better than Wang's. The former succeeds in reproducing the original artistic conceptions. It seems as if the TL readers are reading an idiomatic English essay describing scenery. Like the original text, the version by Zhu Chunshen is provided with aesthetic values: the original language beauty in sense, form and sound is represented through proper wording and phrasing, rhetorical devices and sentence patterns, successfully reproducing the original artistic conceptions. What impresses the author most is that Zhu Chunshen perfectly reproduces the original musicality in the version, which sets a good example in handling this problem in the translation of lyric prose.

\section{How to Achieve Desirable Artistic EfFects in Prose Translation}

With regard to the translation of lyric prose, the translator should bear in mind how to achieve the desirable artistic effects in the translated text besides transferring the original meaning. Only when the artistic effects are reproduced can a translation attain the stage of aesthetic appreciation. The translator may take "spiritual similarity" as his aesthetic pursuit when translating Chinese lyric prose into English. This term advocated by the famous Chinese translator Fu Lei means conveying the original artistic conceptions in the target language without having to stick rigidly to the original linguistic form.

The notion of "spiritual similarity" or "conveying spirit" stresses the transfer of the original flavor, just as what Mao Dun, a 20th century Chinese novelist, cultural critic, and journalist says, "If the version is not able to keep the 'romantic charm' contained in the original, much of the moving power will evidently be lost." A translator should not content himself with such translations as being literally accurate while artistically lifeless. The above English version by Zhu Chunshen is fully justified in doing so. The translator breaks the framework of the original linguistic form and reorganizes the sentence structure, thus achieving spiritual similarity by reproducing the artistic conceptions and the content of the original. Let us analyze the above-mentioned example from this perspective:

月光如流水一般, 静静地泻在这一片叶子和花上。薄薄的青雾浮起在荷塘里。叶子和花仿佛在牛乳中洗过一 样, 又象笼着轻纱的梦。

The moon sheds her liquid light silently over the leaves and flowers, which, in the floating transparency of a bluish haze from the pond, look as if they had just been bathed in milk, or like a dream wrapped in a gauzy hood.

The translator does not copy the original sentence pattern in a mechanical way. In order to make the version sound like fluent and idiomatic English, he renders the original three sentences into a long sentence with an attributive clause, embodying hypotaxis - the characteristic feature of English. In this way, the English version becomes more compact and coherent. And in the above discussion, the choice of words in this English version has been fully analyzed. Thus, not only is the original meaning represented completely, but also the soft tone and the hazy atmosphere are conveyed to the TL readers.

However, "spiritual similarity" as the end-result of the translation of lyric prose does not mean that the translator is entitled to give no consideration to formal similarity. It cannot be denied that spiritual similarity is based on formal similarity. Without similarity in form, spiritual similarity will certainly be deprived of its basis. An ideal translated text is usually thought to be adequate both in form and in spirit, but as far as the translation of lyric prose is concerned, especially when the two aspects cannot be realized at the same time, the translator has to put more stress on similarity in spirit than similarity in form. As compared with the former, the latter is only of secondary importance.

In pursuit of "spiritual similarity", the author has a try at translating one paragraph in Hetang Yuese:

曲曲折折的荷塘上面, 弥望的是田田的叶子, 叶子出水很高, 像亭亭的舞女的裙。层层的叶子中间, 零星地 点缀着些白花, 有哀娜地开着的; 有羞涩地打着朵的; 正如一粒粒的明珠, 又如碧天里的星星, 又如刚出浴的 美人。微风过处, 送来缕缕清香, 仿佛远处高楼上渺茫的歌声似的。这时候叶子和花也有一丝的颤动, 像闪电 般, 雬时传过荷塘的那边去了。叶子本是肩并肩密密的挨着, 这便宛然有了一道凝碧的波痕。叶子底下是脉脉 的流水, 遮住了, 不能见一些颜色; 而叶子却更见风致了。

As far as one could see, the pond with tortuous margins was overspread with a mass of leaves, which rose high above the water like the skirts of slim dancing girls. And layers of leaves were starred with white lotus flowers, some gracefully open, others bashfully in bud, like sparkling pearls, stars in an azure sky, or beauties just out of the bath. A breeze carried with it breaths of fragrance, like the faint singing drifting from some distant tower. At this moment, a quiver ran through the leaves and flowers, which reached to the far end of the pond with lightening speed. This caused a wave of emerald among the leaves that had rubbed shoulders with each other. Under them was the softly running water, hidden from sight, with its color invisible, but the leaves looked more graceful than ever before.

\section{CONClusion}


Zhu Ziqing's prose works are characterized by the artistic values. The aesthetic values in his prose works are created by the writer and realized through the reader's aesthetic experience. The translation of lyric prose is actually a process of reproducing the original artistic features. To fully represent the original aesthetic values in the target language, a translator has to play the double role of both "reader" and "writer". Through the comparative study of two English versions of his famous Hetang Yuese, it is concluded that "similarity in spirit" can be viewed as the aesthetic pursuit of a translator as well as the end-result of the translation of lyric prose. The translator does not have to strictly adhere to the original linguistic form. He is, however, supposed to understand the original artistic features thoroughly, and then take full advantage of the target language to reproduce the language techniques and artistic conceptions of the original.

\section{REFERENCES}

[1] Baker, M. (2000). In other Words: A Coursebook on Translation. Beijing: Foreign Language Teaching and Research Press.

[2] Bascom, J. (1999). Aesthetics - Or the Science of Beauty. Bristol: Thoemmes Press.

[3] Feng Qinghua. (2002). Stylistic Translation. Shanghai: Shanghai Foreign Language Education Press.

[4] Lin Yupeng. (2002). A Theory of Markedness and the Stylistic Markedness of Literary Translations. Chinese Translators Journal. (5): 71-76.

[5] Newmark, P. (2001). Approaches to Translation. Shanghai: Shanghai Foreign Language Education Press.

[6] Nida, E. A. (1993). Language, Culture and Translating. Shanghai: Shanghai Foreign Language Education Press.

[7] Nida, E. A. (2001). Language and Culture: Contexts in Translating. Shanghai: Shanghai Foreign Language Education Press.

[8] Zhang Jin. (1987). The Principles of Literary Translation. Kaifeng: Henan University Press.

[9] Zhang Peiji. (1999). Selected Modern Chinese Prose Writings. Shanghai: Shanghai Foreign Language Education Press.

[10] Zheng Dahua. (2002). Literary Translation Lying in the Result of Aesthetic Appreciation. Chinese Translators Journal. (4): $42-44$.

Ying Yang was born in Shandong Province in 1975. She received her Master's degree in English Language and Literature from Shandong University, China in 2003. She is currently a lecturer in School of International Education, Shandong Economic University. Her research interests include translation studies and cross-cultural communication. 